\title{
Near Infrared Spectra of the Outer Layer of Flour of Stored Milled Rice
}

\author{
Kyouko KaICHI, Midori KaSAI, ${ }^{*}$ Keiko HataE and Atsuko Shimada \\ School of Human Life and Environmental Science, Ochanomizu University, Otsuka 2-1-1, Bunkyo-ku, Tokyo 112, Japan
}

Received January 29, 1997; Accepted July, 25, 1997

Near infrared (NIR) diffuse reflectance spectrophotometry was applied to measure stored milled rice by focusing on the outer layer flour. Rice grains milled $90 \%$ were stored at $37^{\circ} \mathrm{C}$ and $75 \%$ humidity for $0-45$ days. NIR and chemical analyses were performed separately on the outer and inner layers and whole flours of the sample. The most sensitive variation during storage of the absorption intensity by NIR is found on the outer layer flour at the near-infrared region of 2300-2310 $\mathrm{nm}$ which corresponds to fats; the fat content of the outer layer extracted by ether was about 15 times that of the whole layer flour.

Keywords: outer layer flour, milled rice, near infrared spectroscopy, storage

Near-infrared (NIR) spectroscopic analysis is one of the most sensitive methods that can be applied to characterize various infrared-active food materials. This method is versatile and convenient because it is nondestructive and rapid (Onda et al. 1994; Hong et al. 1994). It has been employed to evaluate the palatability of rice (Iwamoto, 1992). In this work, we attempt to analyze stored milled rice by NIR. We have focused on the outer layer analysis to develop a sensitive NIR method for monitoring the change in stored rice.

It is well-known that the decrease in the palatability of milled rice during storage is caused by changes in the lipid (Yasumatsu et al., 1964, 1965; Shibuya et al., 1974) and protein compositions (Moritaka et al., 1971) and their combination with starch (Moritaka \& Yasumatsu, 1972). The content of free fatty acids increases due to the degradation of neutral fat during storage (Shibuya et al., 1974). Phospholipids decrease rapidly prior to the degradation of non-polar lipids (Takano, 1989). These components other than starch are present more in the outer layer of milled rice than in the interior (Barber, 1972). This is the reason why we pay attention to the outer layer analysis.

\section{Materials and Methods}

Sample rice Five samples of "Nipponbare" grown in Shiga Prefecture (1995) were used. Brown rice was stored at $4^{\circ} \mathrm{C}$ in kraft paper bags. Brown rice was milled $90 \%$ in a polishing machine (Toyo Tester, Toyo Seiki Co., Ltd., Tokyo).

Rice storage Milled rice grains of $265 \mathrm{~g}$ in a mesh bag made of polyethylene $(210 \times 110 \mathrm{~mm})$ were placed in a vessel $(250 \times 120 \times 45 \mathrm{~mm})$ having upper and lower sections. Saturated $\mathrm{NaCl}$ solution $(100 \mathrm{ml})$ was placed in the lower section to maintain the humidity at $75 \%$ relative humidity. The milled rice in the vessel was stored at $37^{\circ} \mathrm{C}$ for $0-45$ days.

Grinding Milled rice grains after storage were ground in a grinder (Cyclone Sample Mill, UDY Corporation, USA)

*To whom all correspondence should be addressed to a flour form (whole). The outer layer was milled $90-86 \%$ by a miller (Satake Grain Testing Mill, Tokyo). The flour was sieved through $355 \mu \mathrm{m}$ apertures. The inner layer milled 86 $-0 \%$ was prepared by a grinder.

Measurement of components Moisture contents were measured by drying at $135^{\circ} \mathrm{C}$ for $3 \mathrm{~h}$. Crude fat contents were measured using ether in a Soxhlet apparatus operated for 24 h. Crude protein contents were determined by the Kjeldahl method. Crude ash contents were obtained by heating the samples at $550^{\circ} \mathrm{C}$ for $15 \mathrm{~h}$.

Defatting Ether was added to the outer layer flour, and the mixture was kept at $20^{\circ} \mathrm{C}$ for $24 \mathrm{~h}$ with stirring. The ratio of the solvent to the sample was $5: 1(\mathrm{v} / \mathrm{v})$. After filtration, the flour was dried at room temperature for several hours to remove the solvent.

NIR analysis NIR analysis was performed using an NIR system Model 6500 (NIRECO Co., Ltd., Tokyo) from 1100 to $2500 \mathrm{~nm}$ at intervals of $2 \mathrm{~nm}$. The flour samples of about $6 \mathrm{~g}$ were placed in the cell (for powder), and the diffuse reflectance spectra were measured at room temperature and recorded as $\log (1 / R)$ ( $R$ : reflectance).

\section{Results and Discussion}

Comparison of components of outer and inner layers and whole flours First of all, we mechanically separated the outer and inner layer portions to examine how the chemical components differed. As shown by the results of the chemical analysis in Table 1, the crude protein, fat and ash are present more in the outer layer than in the inner layer and the whole. This is true not only for the control rice but also for the stored sample. The ratio of the crude fat extracted by ether in the outer layer to that in the whole amounts to $15: 1$. Although the outer layer flour is composed of only about $4 \%(w / w)$ of the whole, almost all the crude fat is localized in the outer layer.

After the $\mathbf{4 5}$ day storage, the crude fat showed a significant change only in the outer layer; a $t$-test was done. Although crude protein is distributed more in the outer layer, it was 
Table 1. Comparison of components in the outer, inner layers and whole flours (\%).

\begin{tabular}{|c|c|c|c|c|c|}
\hline Sample & Storage days & Moisture & Crude protein & Crude fat & Crude ash \\
\hline \multirow[t]{2}{*}{ Outer layer } & 0 & $12.6 \pm 0.2$ & $15.0 \pm 0.1$ & $4.6 \pm 0.02$ & $2.3 \pm 0.04$ \\
\hline & 45 & $12.5 \pm 0.3$ & $14.9 \pm 0.1$ & $4.1 \pm 0.02$ & $2.3 \pm 0.03$ \\
\hline \multirow[t]{2}{*}{ Inner layer } & 0 & $13.4 \pm 0.2$ & $5.0 \pm 0.1$ & $0.2 \pm 0.04$ & $0.2 \pm 0.01$ \\
\hline & 45 & $13.5 \pm 0.2$ & $5.0 \pm 0.1$ & $0.1 \pm 0.05$ & $0.2 \pm 0.01$ \\
\hline \multirow[t]{2}{*}{ Whole } & 0 & $13.2 \pm 0.1$ & $5.3 \pm 0.1$ & $0.4 \pm 0.02$ & $0.3 \pm 0.02$ \\
\hline & 45 & $13.3 \pm 0.2$ & $5.4 \pm 0.2$ & $0.3 \pm 0.02$ & $0.3 \pm 0.01$ \\
\hline
\end{tabular}

Samples were stored at $37^{\circ} \mathrm{C} / 75 \% \mathrm{RH}$.
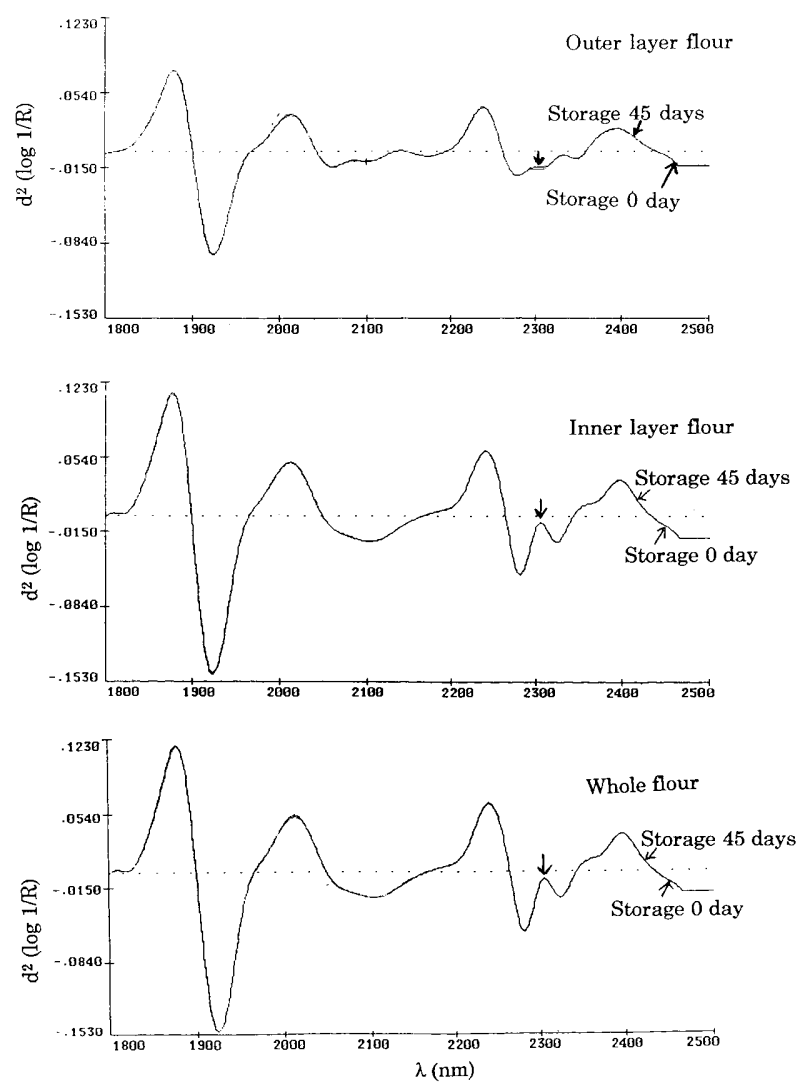

Fig. 1. Second derivative near-infrared spectra of the outer, inner layers an whole flours of milled rice. $R$, reflectance; $\lambda$, wavelength. The spectra for th 0 and 45 storage days overlap each other in all the layers. The inner layer and the whole show exactly the same spectra.

hardly affected by storage. These results correspond to the previous reports that the taste and flavor of cooked rice are improved by increasing the degree of polishing (Kainuma, 1979), thus defatting the milled rice (Moritaka et al., 1971).

Standing time-dependent NIR spectra of outer layer flour As suggested above, the NIR intensity of the outer layer flour can be useful as a sensitive measure of the storage change in milled rice.

We have obtained the NIR spectra in the region of 1800 $2500 \mathrm{~nm}$ where the powder samples provide high quality spectra. In Fig. 1, the NIR spectra of the control (not stored) and that of the stored sample for 45 days are compared. It is found that a detectable change in the spectra is observed at 2300-2310 nm only in the outer layer flour and that this band becomes weaker with storage time.

How the intensity of the band at $2300-2310 \mathrm{~nm}$ for the

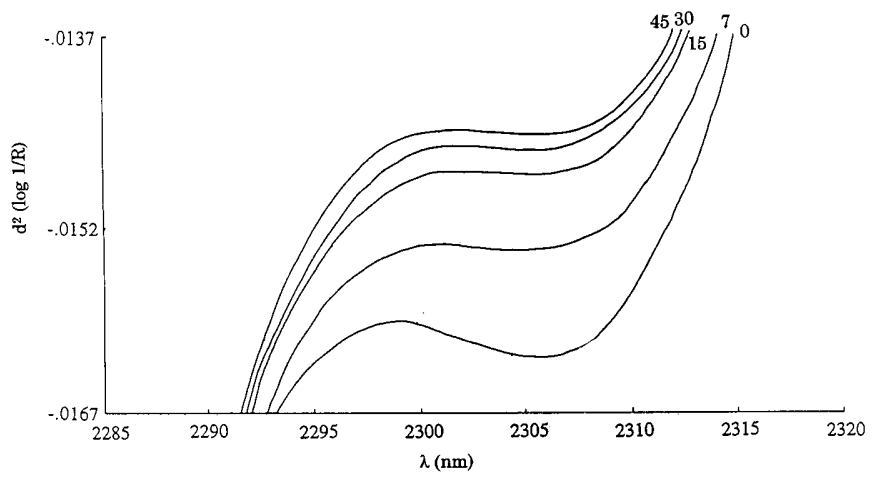

Fig. 2. Storage time dependence of second derivative near-infrared spectra of the outer layer flour of milled rice. $R$, reflectance; $\lambda$, wavelength. The curves are $0,7,15,30$ and 45 days.

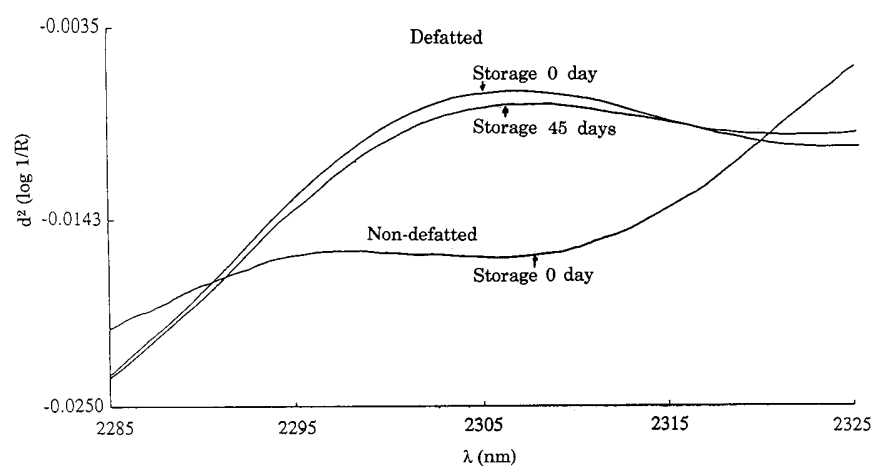

Fig. 3. Comparison of second derivative near-infrared spectra of defatted and non-defatted outer layer of milled rice. $R$, reflectance; $\lambda$, wavelength.

outer layer flour varies with storage time is illustrated by the expanded spectra in Fig. 2. We can observe the change in the 2300-2310 $\mathrm{nm}$ band as a sensitive NIR measure. Analysis of the spectra changes over the whole wavelength region has lead us to conclude that the NIR band at $2300-2310 \mathrm{~nm}$ provides a potential measure of the freshness of rice and that we need to focus on the outer layer portion of rice.

Although the NIR band at $2300-2310 \mathrm{~nm}$ has been variously interpreted (Aramaki et al., 1995; Kamishikiryo et al. 1992), the present study is in favor of the assignment to fats. To confirm this, we have examined the effect of defatting on the NIR band. If the assignment is precise, the defatting is expected to have a remarkable effect on the spectra.

Figure 3 shows the second-derivative spectra of the defatted flour of the outer layer of the control and the 45 day stored 
samples together with those of the non-defatted flour of the control. Ether used here for the defatting is unable to extract fats in the starch, the starch-fatty acid complex. Therefore, the disappearance of the absorption at $2300-2310 \mathrm{~nm}$ after the defatting cannot be ascribed to bound fats but to extraneous lipids. It is concluded that the spectra change in NIR in the outer layer flour of stored milled rice is associated with the labile lipids.

Acknowledgments We are grateful to Mr. K. Tatsubayashi of Nireco Co., Ltd. for providing the NIR equipment, and to advice on Dr. T. Horino of Chugoku National Agricultural Research Institute for valuable NIR analysis.

\section{References}

Aramaki, I., Fukuda, K., Hashimoto, T., Ishikawa, T., Kizaki, K. and Okazaki, N. (1995). Near infrared diffuse reflectance spectrophotometric analysis of mycelial weight in rice koji and search for characteristic wavelengths for mycelia. Seibutsu-kogaku, 73, 33-36 (in Japanese).

Barber, S. (1972). "Rice Chemistry and Technology." Am. Assoc. Cereal Chem. Incorp., St. Paul Min., pp. 215-262.

Hong, J., Koseki, S. and Yasumoto, K. (1994). Analysis of peroxide values in edible oils by near infrared spectroscopy. Nippon Shokuhin Kogyo Gakkaishi, 41, 277-280 (in Japanese).

Iwamoto, M. (1992). Present status of rice taste meter. Japan Food Science, 10, 38-45 (in Japanese).
Kainuma, Y. (1979). The polishing effect of stored aged rice on the quality of cooked rice. Kaseigaku Zasshi, 30, 672-678 (in Japanese).

Kamishikiryo, H., Hasegawa, K., Takamura, H. and Matoba, T. (1992). Near infrared spectroscopic measurements of protein content in oil/water emulsions. J. Food Sci., 57, 1239-1241.

Moritaka, S., Sawada, K. and Yasumatsu, K. (1971). Effect of fat extraction on rice quality and storage deterioration of defatted rice. Eiyo to Syokuryo, 24, 457-460 (in Japanese).

Moritaka, S. and Yasumatsu, K. (1972). The effect of sulfhydryl groups on storage deterioration of milled rice studies on cereals (Part 10). Eiyo to Syokuryo, 25, 59-62 (in Japanese).

Onda, T., Abe, H., Matsunaga, A., Komiyama, Y. and Kawano, S. (1994). Analysis of gelatinization of starch by near infrared spectroscopy. Nippon Shokuhin Kogyo Gakkaishi, 41, 886-890 (in Japanese)

Shibuya, N., Iwasaki, T., Yanase, H. and Chikubu, S. (1974). Studies on deterioration of rice during storage. Nippon Shokuhin Kogyo Gakkaishi, 12, 597-603 (in Japanese).

Takano, T. (1989). Studies on the mechanism of lipid-hydrolysing in rice bran. Nippon Shokuhin Kogyo Gakkaishi, 36, 519-524 (in Japanese).

Yasumatsu, K., Moritaka, S. and Kakinuma, T. (1964). Effect of the change during storage in lipid composition of rice on its amylogram. Agric. Biol. Chem., 28, 265-272.

Yasumatsu, K., Moritaka, S., Bichu, S., Ishi, K., Shimazono, H. and Fujita, E. (1965). Flavor deterioration of polished rice during storage. Eiyo to Syokuryo, 18, 130-133 (in Japanese). 